\title{
ANATOMIA DA MADEIRA E CASCA DA BRACATINGA, Mimosa scabrella Benth.
}

\author{
José Newton Cardoso Marchiori \\ Departamento de Ciências Florestais - Centro de Ciências Rurais \\ UFSM - Santa Maria, RS
}

\section{RESUMO}

São descritos os caracteres gerais, macroscópicos e microscópicos da madeira de Mimosa scabrella Benth., bem como a estrutura de sua casca. A anatomia da madeira é comparada com referências da literatura para espécies afins. Os caracteres observados incluem vasos com placas de perfuração simples, pontoações alternas e ornamentadas, parênquima paratraqueal, fibras libriformes, raios homogêneos de células procumbentes e presença de estratificação. Na estrutura da casca destacam-se o crescimento de dilatação dos raios na casca mediana e o líber duro, que forma pequenos grupos na casca interna.

Palavras-chave: Bracatinga, Mimosa scabrella Benth., Leguminosae, Mimosoideae, Anatomia da Madeira, Anatomia da casca.

\section{SUMMARY}

The general, macroscopic and microscopic features of the wood of Mimosa scabrella Benth. are described, as well as its bark anatomy. The wood and bark structure are compared with literature references. Vessels with simple perforation plates, alternate and vestured intervascular pitting, libriform fibres, homogeneous rays with procumbent cells and the conspicuous ripple marks in radial sections, are the most important features in this wood. Irregular groups of phloematic fibres in the inner bark, surrounded by chrystalliferous parenchyma strands, and the tangencial growing of rays in the middle bark, are the most important features observed in the bark.

Keywords: Bracatinga, Mimosa scabrella Benth., Leguminosae, Mimosoideae, Wood Anatomy, Barknatomy 


\section{INTRODUÇÃO}

A bracatinga é uma árvore de 15 a $20 \mathrm{~m}$ de altura, originária do sul do Brasil. Sua área natural de ocorrência se estende desde Goiás até o nordeste do Rio Grande do Sul (RAMBO, 1953, 1966; HOEHNE, 1930). Na Argentina nunca foi encontrada em estado silvestre (BURKART, 1948)

Trata-se da espécie de Mimosa de maior porte nesta região, tendo importância florestal e madeireira. A bracatinga produz troncos de 10 a $20 \mathrm{~cm}$ de diâmetro e alta copa flabeliforme em idade adulta. A folhagem destaca-se pelo tom acinzentado, resultante da pilosidade que reveste os raminhos e folhas compostas bipinadas. As flores amarelas são produzidas no inverno. Os frutos amadurecem de novembro a fevereiro (INOUE et al., 1984).

A bracatinga é árvore característica e quase exclusiva dos pinhais, sendo muito abundante em matas semi-devastadas e secundárias (KLEIN, 1960). Forma, freqüentemente, associações puras em terrenos onde a vegetação principal foi destruída e queimada, "sendo espécie pioneira, de rápido crescimento, heliófila e pouco exigente quanto a condições físicas do solo (REITZ et al., 1978)

A casca é áspera, marrom ou castanha quando jovem e acinzentada ou de cor preta na fase adulta, apresentando normalmente manchas brancas ou de outras cores, produzidas por fungos e líquens.

A madeira é moderadamente pesada, tendo uma massa específica variável entre 0,67 (BROTERO, 1956; JANKOWSKY et al., 1990; REITZ et al., 1983) e 0,77 (SILVA, 1967; PEDROSO \& MATTOS, 1987). Possui alta retratibilidade, resistência mecânica média a alta, baixa durabilidade natural quando em contato com o solo e dificil permeabilidade a produtos preservativos. É dificil de serrar, mas fácil de ser aplainada ou lixada, obtendo-se superficie lisa. Oferece dificuldades na secagem (rachaduras, colapso), requerendo processo a baixas temperaturas.

A madeira é mais utilizada como lenha ou para a obtenção de celulose e carvão (MAINIERI, 1973). A celulose sulfato da bracatinga oferece razoável resistência à tração e ao arrebentamento, baixa resistência ao rasgo e rendimento semelhante ao obtido com a madeira de eucalipto (BARRICHELO, 1971; BARRICHELO \& FOELKEL, 1975). O carvão ativo da bracatinga é de boa qualidade (BÜHRER, 1952).

A anatomia da madeira da bracatinga é ainda pouco conhecida, merecendo um estudo mais detalhado. A estrutura da casca ainda não havia sido descrita. 


\section{REVISÃO DE LITERATURA}

O gênero Mimosa é um dos mais conhecidos das leguminosas, por sua grande difusão nos países de clima quente e por ter dado origem a um dos principais sub-grupos da família. Este nome é muito antigo, tendo agrupado quase todas as leguminosas mimosoideas conhecidas no tempo de Linnaeus. Cabe destacar que das 47 espécies relacionadas no "Codex Linneamıs", apenas 6 são atualmente reconhecidas como verdadeiras mimosas, tendo as demais sido distribuídas em 16 gêneros distintos. Bentham e De Candolle, dentre outros eminentes botânicos do século XIX, foram os responsáveis por esta diferenciação genérica.

O gênero Mimosa compreende atualmente mais de 400 espécies. É predominantemente americano, contando com escassos representantes na África e Ásia. No continente americano é encontrado em todas as regiões quentes, desde o sul dos Estados Unidos até o Uruguai e centro da Argentina. Falta apenas no Chile, Patagônia e região andina (BURKART, 1952)

O melhor conhecedor do gênero foi indubitavelmente George Bentham (1800 1884). Suas monografias "Revision of the sub-order Mimoseae", datada de 1875 , e sua contribuição para a "Flora Brasiliensis" (1876) continuam básicas, apesar de terem sido publicadas há mais de um século. As numerosas espécies descritas mais recentemente, tem sido incluidas sobretudo em obras floristicas de distintas regiões sul-americanas, por renomados especialistas como BURKART $(1948 ; 1952 ; 1959 ; 1967 ; 1979 ; 1987)$ e BARNEBY $(1985)$

O sistema de BENTHAM (1875) continua a ser utilizado para a classificação das mimosas. De acordo com o mesmo, o gênero compreende as secções Habbasia e Eumimosa. Na primeira, incluem-se as espécies com flores diplostêmones, ao passo que em Eumimosa, as flores contam com número de estames igual ao de pétalas.

Mimosa scabrella, com suas flores isostêmones e corola tetrâmera, insere-se portanto na seç̧ão Eumimosa. A presença de flores amarelas e de abundantes pêlos multicelulares ramificados em raminhos, flores, pedúnculos, perianto e frutos de Mimosa scabrella, justificam a inclusão da espécie na série Lepidotae, de Bentham.

A anatomia da madeira foi pouco investigada no gênero, mercê do limitado interesse econômico da maioria de suas numerosas espécies

Em estudo de 11 madeiras argentinas, COZZO (1951) concluiu que o gênero é estruturalmente heterogêneo, devido à ampla variação anatômica encontrada no material examinado. O autor agregou, a este respeito, não haver no grupo "un rasgo comun que las enlace". 
$\mathrm{Na}$ chave de identificação das espécies estudadas, COZZO (1951) refere para Mimosa scabrella a presença de poros solitários ou geminados, de parênquima axial abundante ou muito abundante, de raios não exclusivamente unisseriados e de estratificação incompleta, porém uniforme. Este último caráter foi observado apenas para a espécie em estudo e para Mimosa adpressa, no conjunto das 11 espécies examinadas.

Das espécies sul-brasileiras foram publicados estudos descritivos apenas para Mimosa daleoides (MARCHIORI, 1982), Mimosa cruenta (MARCHIORI, 1985), Mimosa bimucronata (MARCHIORI, 1993) e Mimosa sparsa (MACCARI \& MARCHIORI, 1994). A ontogenia do caule da bracatinga foi descrita por MARCHIORI (1988).

A literatura sobre a estrutura da casca é ainda mais reduzida do que a de madeiras. Neste particular destaca-se o trabalho de ROTH (1977), que estudou 22 espécies arbóreas de leguminosas mimosoídeas da Venezuela, pertencentes a 7 diferentes gêneros. O gênero Mimosa, não foi contudo investigado. De acordo com a autora, a sub-família constitui um grupo relativamente homogêneo quanto à estrutura do floema, apresentando o seguinte conjunto de caracteres anatômicos básicos

- Líber duro na forma de fibras típicas, agrupadas em placas tangenciais estreitas, alternantes com faixas de tecido parenquimático;

- Ausência de células pétreas na casca interna;

- Raios não raras vezes multisseriados;

- Ausência de canais secretores, mas com células secretoras em curtas fileiras tangenciais;

- Crescimento de dilatação moderado, havendo a formação de células pétreas no final da casca mediana;

- Súber estratificado e feloderma com células pétreas, tendente à estratificação.

ROTH (1977) encontrou semelhanças entre a estrutura anatômica da casca das Mimosoideae e família Sapotaceae, sobretudo quanto ao agrupamento do líber duro e formação de células secretoras.

Para Mimosa bimucronata, MARCHIORI (1993) registrou a presença de liber duro em faixas tangenciais descontínuas, envolvidas por células parenquimáticas geralmente cristaliferas, o curso irregular dos raios na casca interna e a formação de cunhas de parênquima na casca mediana. $\mathrm{O}$ autor não observou qualquer tipo de estratificação na casca. 


\section{MATERIAL E MÉTODOS}

O material estudado consiste de amostras do tronco (madeira e casca) e respectivas exsicatas botânicas, que se encontram depositadas no Herbário do Departamento de Ciências Florestais da Universidade Federal de Santa Maria (HDCF), com os seguintes registros :

- HDCF 85. Curitiba, PR. Marchiori, J.N.C., 28/7/1979.

- HDCF 344. FLONA Passo Fundo, RS. Marchiori, J.N.C., 20/7/1978.

- HDCF 354. FLONA Passo Fundo, RS. Marchiori, J.N.C., 20/7/1978.

Para o estudo anatômico da madeira foram preparadas lâminas de cortes e de macerado. As primeiras foram obtidas em micrótomo de deslizamento, com espessura nominal de 18 $\mu \mathrm{m}$. Usou-se coloração com Acridina-vermelha, Crisoidina e Azul-de-astra (DUJARDIN, 1964), e montagem permanente com "Entellan".

No preparo de lâminas de macerado usou-se solução de Jeffrey (FREUND, 1970), tanto para as amostras de madeira como de casca e o mesmo meio de montagem anteriormente citado

O preparo de cortes anatômicos da casca incluiu o amolecimento de amostras por fervura em água, a inclusão das mesmas em celoidina e seu posterior corte em micrótomo de deslizamento. Na montagem e coloração seguiu-se o descrito, anteriormente, para lâminas de madeira.

Para a descrição do xilema seguiram-se as recomendações da COPANT (1973), com as modificações utilizadas por BURGER (1979). Os dados quantitativos são apresentados na Tabela 1.

A determinação da percentagem ocupada pelos diferentes tecidos da madeira foi realizada em plano transversal, segundo as recomendações de MARCHIORI (1980 b). Para a determinação da percentagem dos diferentes tipos de raios, quanto à sua largura em número de células, usou-se o plano tangencial. Os dados estatísticos incluem valor mínimo, média, valor máximo e desvio padrão, sendo apresentados na Tabela 2.

A cor da madeira foi definida com o uso da Tabela de Cores para Tecidos Vegetais (MUNSELL, 1952).

Para a descrição da casca foram determinados o comprimento e diâmetro de fibras floemáticas, com base em 20 medições de cada caráter por amostra. Os dados estatísticos referentes a estas medições são apresentados na Tabela 3 . 
A fotomacrografia foi obtida em microscópio estereoscópico marca Leitz, modelo Aristofot. Para as fotomicrografias utilizou-se aparelho Carl Zeiss. O registro fotográfico foi realizado em filme Panatomic X-ASA 32, ampliado em papel fotográfico Kodabromid F3.

\section{DESCRIÇÃO DA MADEIRA}

\section{Caracteres gerais}

Madeira de cor palha (Munsell HUE 2,5 Y 8/4), com regiões mais escuras tendendo ao marrom (Munsell HUE 7,5 Y 5/4 - 5/6). Apresenta cerne distinto e alburno muito estreito. É medianamente brilhante, sem odor e gosto distintos, macia ao corte, de grã reta, de textura média e com veteado discreto.

\section{Caracteres macroscópicos :}

Poros: Em distribuição difusa (Figura 1), de numerosos a muito numerosos e com-diâmetro médio. São visiveis a olho nu, desprovidos de conteúdos, solitários ou em múltiplos radiais de 2 a 4 poros. Parênquima axial: Escasso, visivel a olho nu ou com lente de 10 aumentos; tipicamente paratraqueal vasicêntrico, ocasionalmente aliforme até curto-confluente (Figura 1).

Parênquima radial: Quase imperceptivel a olho nu em secção transversal. Raios visivieis sob lente, finos, de muito pouco freqüentes a pouco freqüentes (Figura 1). Quase invisiveis a olho nu em plano tangencial, visíveis sob lente, baixos, não-estratificados. Espelhado contrastado.

Anéis de crescimento: Visiveis a olho nu, fracamente perceptiveis sob lente, evidenciados por uma estreita linha tangencial de tecido mais claro (Figura 1).

Outros caracteres: Líber incluso, máculas medulares e canais secretores axiais ou horizontais, não observados.

\section{Caracteres microscópicos :}

Vasos: Porosidade difusa (Figura 2.A). Poros de muito pouco freqüentes a muito numerosos (2-1027 poros $\left./ \mathrm{mm}^{2}\right)$, de extremamente pequenos a grandes $(28-156-255 \mu \mathrm{m})$ e de paredes pouco espessas $(3-3,5-5 \mu \mathrm{m})$. Poros de secção oval, solitários, em curtos agrupamentos de múltiplos radiais e em múltiplos racemiformes pouco freqüentes (Figura 2.A).

Elementos vasculares de muito curtos a longos (190 - 351 - $510 \mu \mathrm{m})$, desprovidos de espessamentos espiralados e outras estriações nas paredes. Poros do cerne, freqüentemente, com 
conteúdos de cor escura e aspecto de gomo-resina; com ou sem apêndices, curtos (20 - 55 - 160 $\mu \mathrm{m})$, em uma ou em em ambas as extremidades. Placa de perfuração simples, quase transversal (Figura 3.A-E).Pontoações intervasculares de pequenas a médias $(5-8,3-11 \mu \mathrm{m})$, de forma oval a poligonal. Possuem abertura externa estreita, em forma de fenda horizontal, inclusa, guarnecida e abertura interna estreita, exclusa, geralmente longo-coalescente, em posição horizontal ou inclinada (Figura 3.F)

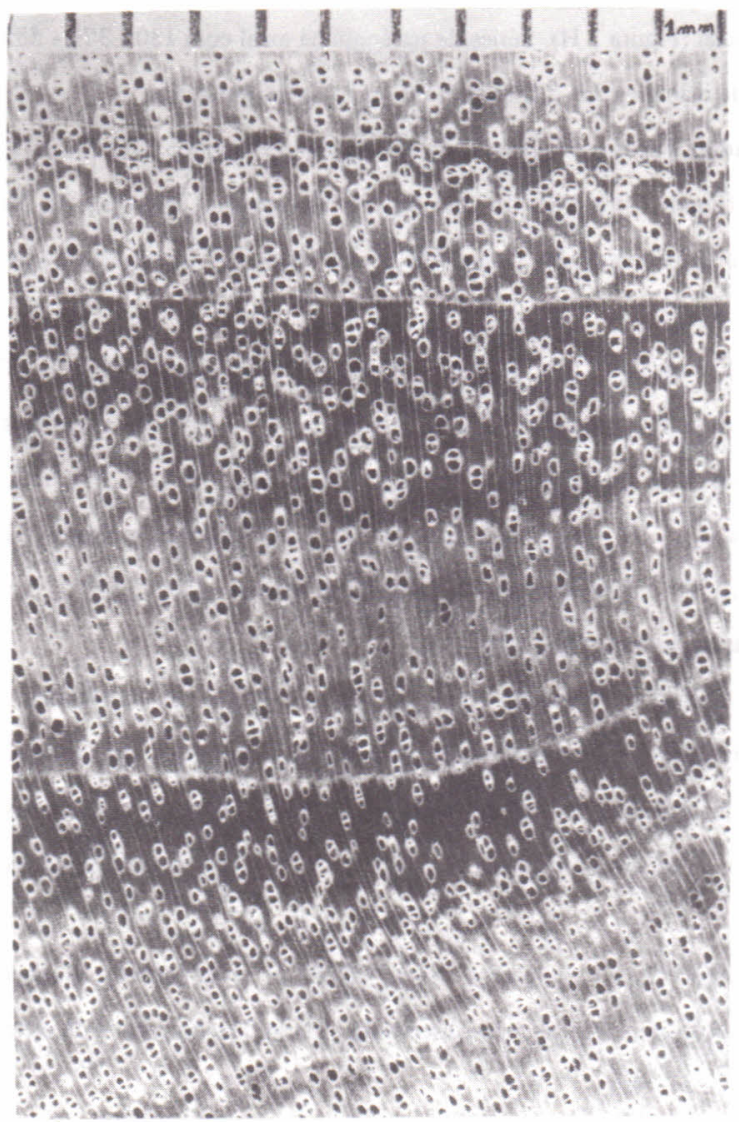

FIGURA 1. Fotomacrografia $(10 \mathrm{X})$ da secção transversal da madeira. São vistos anéis de crescimento, raios estreitos, poros numerosos e de diâmetro médio e parênquima paratraqueal vasicêntrico

Pontuados raio-vascular e parênquimo-vascular alternos. Pontoações raio-vasculares pequenas (5 $6,2-8 \mu \mathrm{m}$ ) e ornamentadas, tendo abertura inclusa, em forma de fenda horizontal. Pontoações parênquimo-vasculares pequenas $(4-5,8-7 \mu \mathrm{m})$ e ornamentadas, com abertura externa estreita, inclusa e abertura interna estreita, geralmente exclusa, não-coalescente. 
Parênquima axial: Pouco abundante, ocupando $10,8 \%$ do volume da madeira. Parênquima axial estratificado, tipicamente paratraqueal e dos tipos escasso, unilateral, vasicêntrico, aliforme, raramente curto-confluente (Figura 2.A). Em secção transversal muitas vezes não é possível a distinção entre células de parênquima axial e fibras, especialmente no lenho inicial.

Células de parênquima axial fusiformes de 185 - $370-543 \mu \mathrm{m}$ de altura por 5 - $21-45 \mu \mathrm{m}$ de diâmetro tangencial (Figura 3.H). Séries de parênquima axial com 180 - 379 - $555 \mu \mathrm{m}$ de altura por 8 - 22 - $50 \mu \mathrm{m}$ de diâmetro, em 2 (Figura 3.G) ou 3 células por série.

Parênquima radial: Raios homogêneos, pouco freqüentes a pouco numerosos ( 3 - 5 - 8 raios $/ \mathrm{mm}$ ), de tipo normal (Figura 2.C) e desprovidos de células especiais (Figura 2.B). Na extremidade dos raios as células procumbentes são comumente mais altas e mais curtas, tendo com frequeência forma irregular.

Raios unisseriados escassos ( $6 \%$ do total), extrememamente baixos (23 - $127-335 \mu \mathrm{m})$, de extremamente finos a muito finos $(5-12-25 \mu \mathrm{m})$ e com $1-6$ - 17 células de altura (Figura 4.A-B). Raios multisseriados de extremamente baixos a baixos (113 - $561-1.563 \mu \mathrm{m})$, de extremamente finos a estreitos $(13-31-53 \mu \mathrm{m})$ e com $5-31-126$ células de altura. São em sua maioria trisseriados $(61,8 \%)$, com abundantes bi $(17,1 \%)$ e tetrasseriados $(15,8 \%)$, mas raramente com mais de 4 células de largura (Figura 4.C-G).

Fibras: Tecido fibroso proeminente, ocupando $61,6 \%$ do volume da madeira. Fibras libriformes, não-septadas, freqüentemente gelatinosas e dotadas de pontoações simples muito pequenas, mais abundantes em faces radiais da parede (Figura 3.I). Fibras extremamente curtas até curtas (530 $960-1.500 \mu \mathrm{m})$, de estreitas a médias $(13-25-40 \mu \mathrm{m})$, e com paredes delgadas $(2-5-12 \mu \mathrm{m})$

Outros caracteres: Canais secretores, tubos laticíferos e taniniferos, floema incluso, máculas medulares e inclusões inorgânicas, não-observados. Estratificação parcial de elementos vasculares e parênquima axial associado.

Limite de anel de crescimento pouco evidente. Anéis de crescimento distintos, evidenciados pelo lenho tardio, com fibras de paredes espessas (Figura 2.A).

\section{DESCRIÇÃO DA CASCA}

Casca interna: De espessura variável entre 600 e $1.300 \mu \mathrm{m}$, nos espécimes analisados. Líber duro constituído por fibras floemáticas ocasionalmente septadas, comumente gelatinosas, de 1.000 - 
1.378 - $1.750 \mu \mathrm{m}$ de comprimento, por 15 - 22 - $30 \mu \mathrm{m}$ de diâmetro tangencial. Reúnem-se em pequenos agrupamentos, geralmente mais estreitos do que a distância entre dois raios, evidenciando, por vezes, uma tendência para organização tangencial (Figura 5.A). Os feixes de fibras são revestidos, quase totalmente, por séries de parênquima cristalifero, tendo monocristais romboédricos de oxalato de cálcio em câmaras (Figura 5.C).
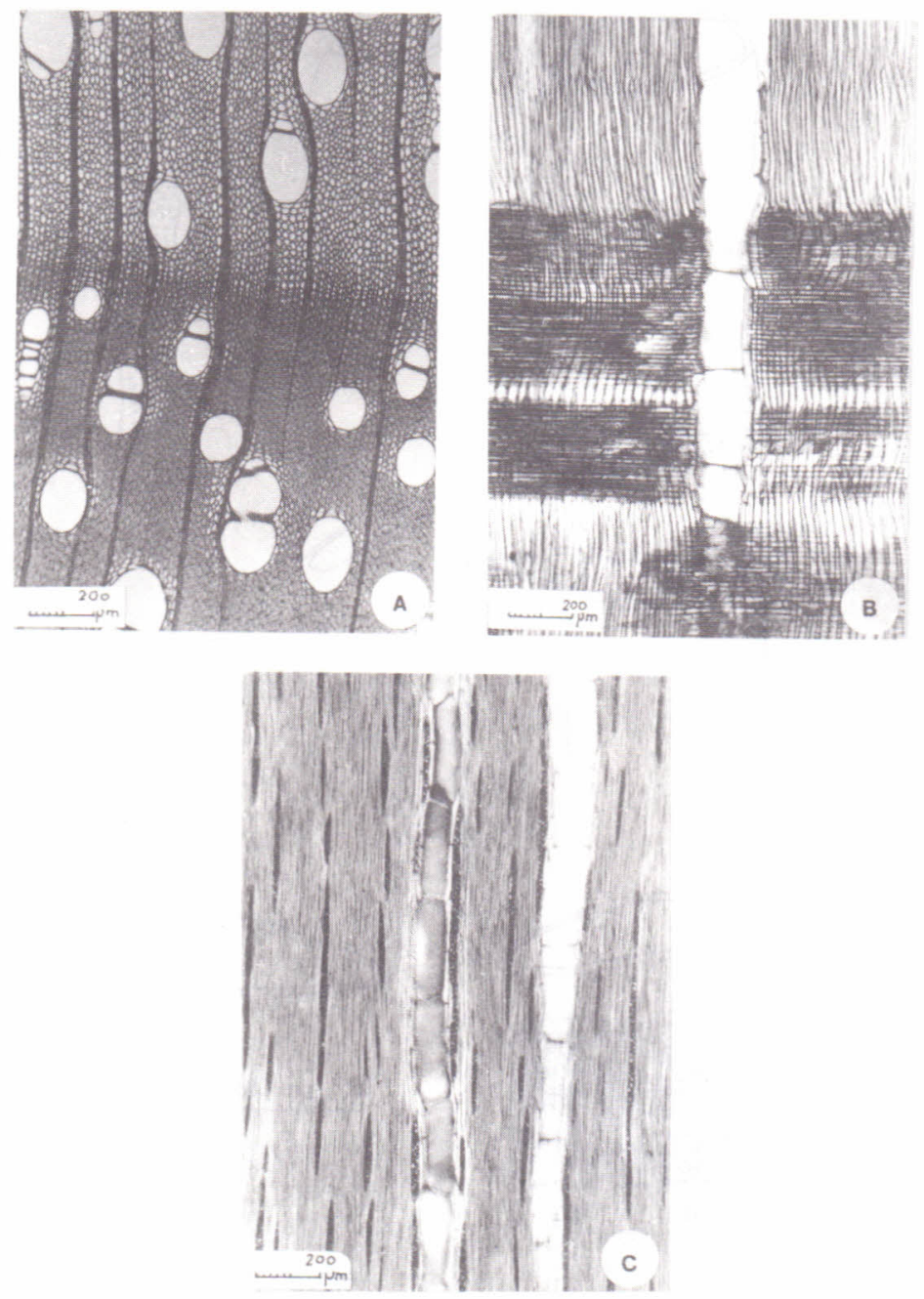

FIGURA 2. Fotomicrografias do xilema secundário. A. Secção transversal, mostrando poros solitários e em curtos múltiplos, parênquima tipicamente paratraqueal e anéis de crescimento marcados por fibras de paredes espessas no lenho tardio. B. Seç̧ão longitudinal radial. C. Raios de tipo normal, em seç̧ão longitudinal tangencial. 
Elementos crivados muito numerosos e sem arranjo característico no líber tenro (Figura 5.A), medindo de $300-349-390 \mu \mathrm{m}$ de comprimento por $22,5-28-32,5 \mu \mathrm{m}$ de diâmetro tangencial. As placas apresentam de 5 a 9 áreas crivadas em arranjo escalariforme, menos freqüentemente reticulado. Áreas crivadas com numerosos poros diminutos. Células acompanhantes desprovidas de cristais

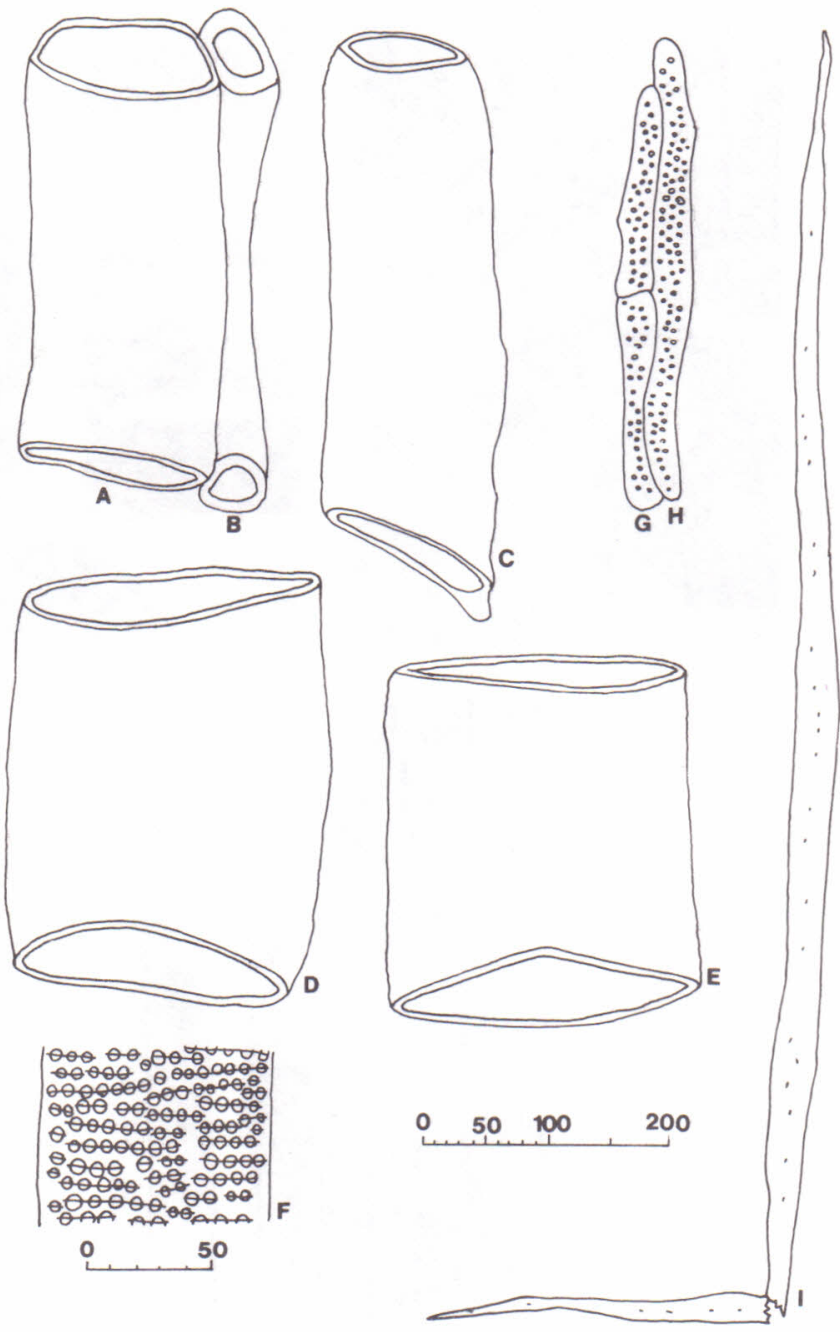

FIGURA 3. Elementos celulares axiais do xilema. A-E. Elementos vasculares. F. Aspecto tangencial da parede de elemento vascular, mostrando o pontuado intervascular alterno e aberturas internas coalescentes a várias pontuações. G. Células de parênquima axial seriado. H. Célula de parênquima axial fusiforme. I. Fibra libriforme. 
Parênquima axial abundante, ocasionalmente com monocristais romboédricos de oxalato de cálcio em câmaras.

Raios semelhantes aos do xilema em secção tangencial (Figura 5.D), homogêneos ou fracamente heterogêneos, tendo uma fileira terminal de células pouco procumbentes, às vezes quadradas ou eretas. Células de parênquima radial desprovidas de cristais.

Elementos crivados, células acompanhantes e células de parênquima axial, nitidamente estratificados em secção radial (Figura 5.C); em secção tangencial o caráter é menos evidente, entbora ainda perceptível (Figura 5.D).

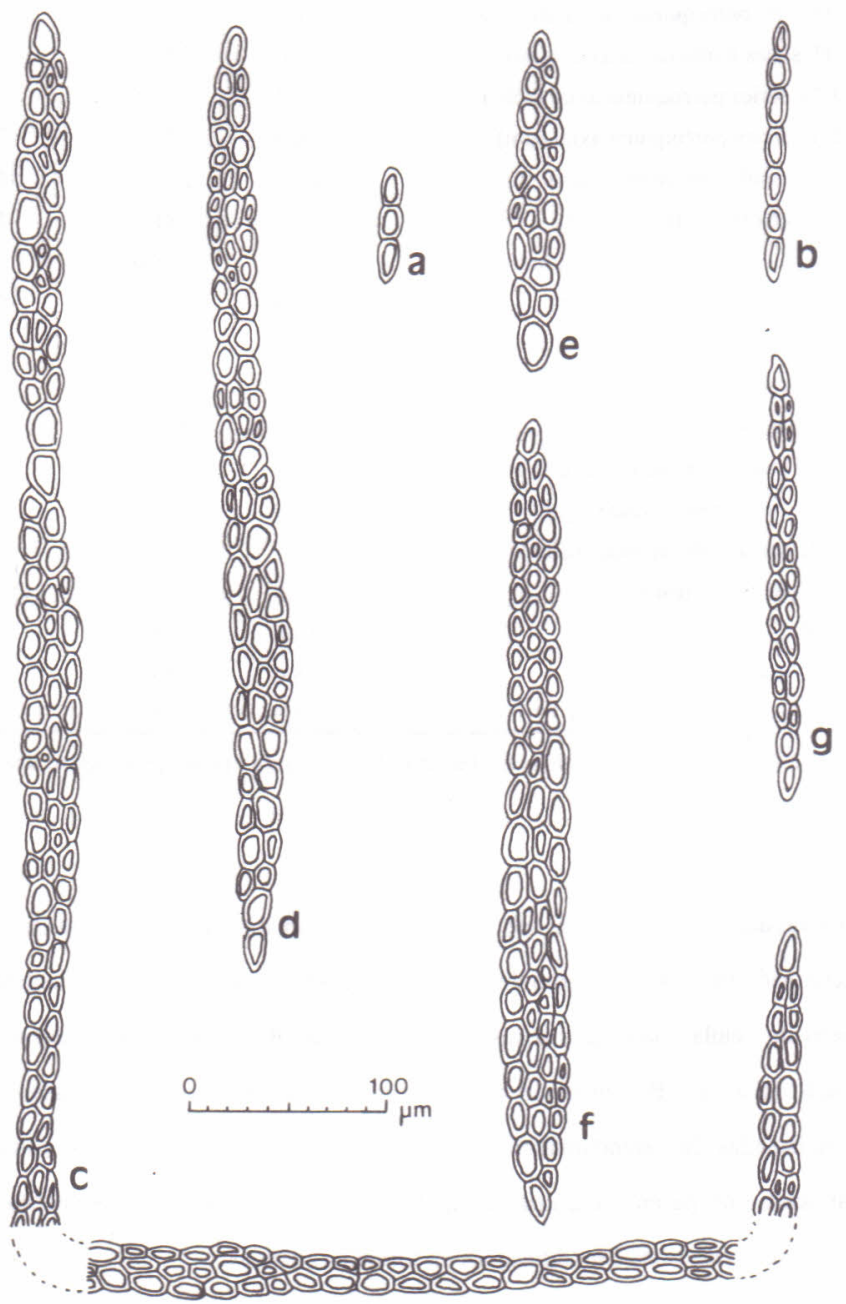

FIGURA 4. Raios xilemáticos em secção longitudinal tangencial. A-B. Raios unisseriados. G. Raio bisseriado. D-E. Raios trisseriados. C-F. Raios tetrasseriados. 
TABELA 1. Dados quantitativos da estrutura anatômica do xilema

\begin{tabular}{|c|c|c|c|c|}
\hline ASPECTO ANATÔMICO & V. MÍNIMO & MÉDIA & V.MÁXIMO & D. PADRÃO \\
\hline 1. Frequeência de poros (poros $/ \mathrm{mm}^{2}$ ) & 2 & 10,0 & 27 & 3,60 \\
\hline 2. C. elementos vasculares $(\mu \mathrm{m})$ & 190 & 351,0 & 510,0 & 48,74 \\
\hline 3. C. de apêndices $(\mu \mathrm{m})$ & 20,0 & 55,0 & 160,0 & 32,73 \\
\hline 4. $\emptyset$ tangencial de poros $(\mu \mathrm{m})$ & 28,0 & 155,9 & 255,0 & 43,99 \\
\hline 5. E. parede de poros $(\mu \mathrm{m})$ & 3,0 & 3,5 & 5,0 & 0,86 \\
\hline 6. $\emptyset$ pont. intervasculares $(\mu \mathrm{m})$ & 5,0 & 8,3 & 11,0 & 1,04 \\
\hline 7. $\emptyset$ pont. raio-vasculares $(\mu \mathrm{m})$ & 5,0 & 6,2 & 8,0 & 0,75 \\
\hline 8. $\emptyset$ pont. parênquimo-vasculares $(\mu \mathrm{m})$ & 4,0 & 5,8 & 7,0 & 0,74 \\
\hline 9. H. séries parênquima axial $(\mu \mathrm{m})$ & 180,0 & 379,0 & 555,0 & 59,09 \\
\hline 10. H. séries parênquima axial (céls.) & 2 & 2,1 & 3 & 0,21 \\
\hline 11. L. séries parênquima axial $(\mu \mathrm{m})$ & 8,0 & 22,0 & 50,0 & 8,85 \\
\hline 12. H. células fusiformes $(\mu \mathrm{m})$ & 185,0 & 370,0 & 543,0 & 65,48 \\
\hline 13. L. células fusiformes $(\mu \mathrm{m})$ & 5,0 & 21,0 & 45,0 & 7,14 \\
\hline 14. Freqüência de raios (raios $/ \mathrm{mm}$ ) & 3 & 5,0 & 8 & 1,02 \\
\hline 15. H. raios unisseriados $(\mu \mathrm{m})$ & 23,0 & 127,0 & 355,0 & 66,55 \\
\hline 16. H. raios unisseriados (céls.) & 1 & 6 & 17 & 3,00 \\
\hline 17. L. raios unisseriados $(\mu \mathrm{m})$ & 5,0 & 12,0 & 25,0 & 3,63 \\
\hline 18. H. raios multisseriados $(\mu \mathrm{m})$ & 113,0 & 561,0 & 1563,0 & 286,96 \\
\hline 19. H. raios multisseriados (céls.) & 5 & 31 & 126 & 30,61 \\
\hline 20. L. raios multisseriados $(\mu \mathrm{m})$ & 13,0 & 31,00 & 53,0 & 7,76 \\
\hline 21. L. raios multisseriados (céls.) & 2 & 3 & 5 & 0,64 \\
\hline 22. C. de fibras $(\mu \mathrm{m})$ & 530 & 960,0 & 1500,0 & 189,72 \\
\hline 23. $\emptyset$ de fibras $(\mu \mathrm{m})$ & 13,0 & 25,0 & 40,0 & 5,62 \\
\hline 24. $\emptyset$ lume de fibras $(\mu \mathrm{m})$ & 5,0 & 15,0 & 30,0 & 5,09 \\
\hline 25. E. parede de fibras $(\mu \mathrm{m})$ & 2,0 & 5,0 & 12,0 & 1,71 \\
\hline
\end{tabular}

C.: comprimento; Ø: diâmetro; L.: largura; E.: espessura; pont.: pontoações; céls.: células

Casca mediana: Proeminente, de 2.000 a $3.000 \mu \mathrm{m}$ de espessura. O início da casca mediana é caracterizado pelo esmagamento de elementos crivados e células acompanhantes, e pelo aumento do número de células parenquimáticas axiais e radiais. Raios com crescimento, principalmente por dilatação (Figura 5.B), iniciando em diferentes posições na casca mediana. A transformação de células isoladas de parênquima radial em esclereidas, verifica-se desde o começo da dilatação. A estratificação do parênquima axial desaparece gradativamente na casca mediana, à medida em que ocorrem novas divisões e modificações na forma das células.

Em secção transversal, a metade externa da casca mediana caracteriza-se pelo alinhamento tangencial crescente das células parenquimáticas, em conseqüência de divisões celulares, segundo 
TABELA 2. Histometria do xilema e percentagem dos tipos de raios quanto à sua largura em número de células.

\begin{tabular}{lrr}
\hline \hline ASPECTO ANATÔMICO & MÉDIA & D. PADRÃO \\
\hline 1. Fração vasos (\%) & 16,1 & 4,63 \\
2. Fração parênquima axial (\%) & 10,8 & 2,52 \\
3. Fração raios (\%) & 11,5 & 2,71 \\
4. Fração fibras (\%) & 61,6 & 5,41 \\
5. Fração raios unisseriados (\%) & 5,1 & 2,09 \\
6. Fração raios bisseriados (\%) & 17,1 & 6,04 \\
7. Fração raios trisseriados (\%) & 61,8 & 8,50 \\
8. Fração raios tetrasseriados (\%) & 15,8 & 11,80 \\
9. Fração raios com + de 4 células (\%) & 0,2 & 0,40 \\
\hline
\end{tabular}

TABELA 3. Medições anatômicas da casca.

\begin{tabular}{lllll}
\hline \hline ASPECTO ANATÔMICO & V. MÍNIMO & MÉDIA & V. MÁXIMO & D. PADRÃO \\
\hline 1. C. Fibras floemáticas $(\mu \mathrm{m})$ & 1000,0 & 1378,0 & 1750,0 & 151,29 \\
2. $\emptyset$ fibras floemáticas $(\mu \mathrm{m})$ & 15,0 & 22,0 & 30,0 & 4,30 \\
3. C. elementos crivados $(\mu \mathrm{m})$ & 300,0 & 349,0 & 390,0 & 16,55 \\
4. $\emptyset$ elementos crivados $(\mu \mathrm{m})$ & 22,5 & 28,0 & 32,5 & 2,54 \\
\hline
\end{tabular}

Ø: diâmetro; C.: comprimento

planos anticlinais (Figura 5.B). A esclerificação aumenta em direção à periferia da casca mediana; não chegando contudo a formar um cilindro compacto de esclereidas. As células pétreas e macroesclereidas ficam isoladas ou em grupos irregulares, no meio das células parenquimáticas vivas. $\mathrm{Na}$ casca mediana não ocorre a proliferação de cristais.

Casca externa : Muito estreita $(30$ a $500 \mu \mathrm{m})$ e formada por sucessivas peridermes em forma de calotas, com tecidos não-peridérmicos isolados (Figura 5.B).

Células de felema extremamente estreitas (cerca de $6 \mu \mathrm{m}$ de diâmetro radial) e fortemente suberizadas.

\section{ANÁLISE DA ESTRUTURA ANATÔMICA}

A estrutura anatômica da madeira de Mimosa scabrella indica um alto grau de 

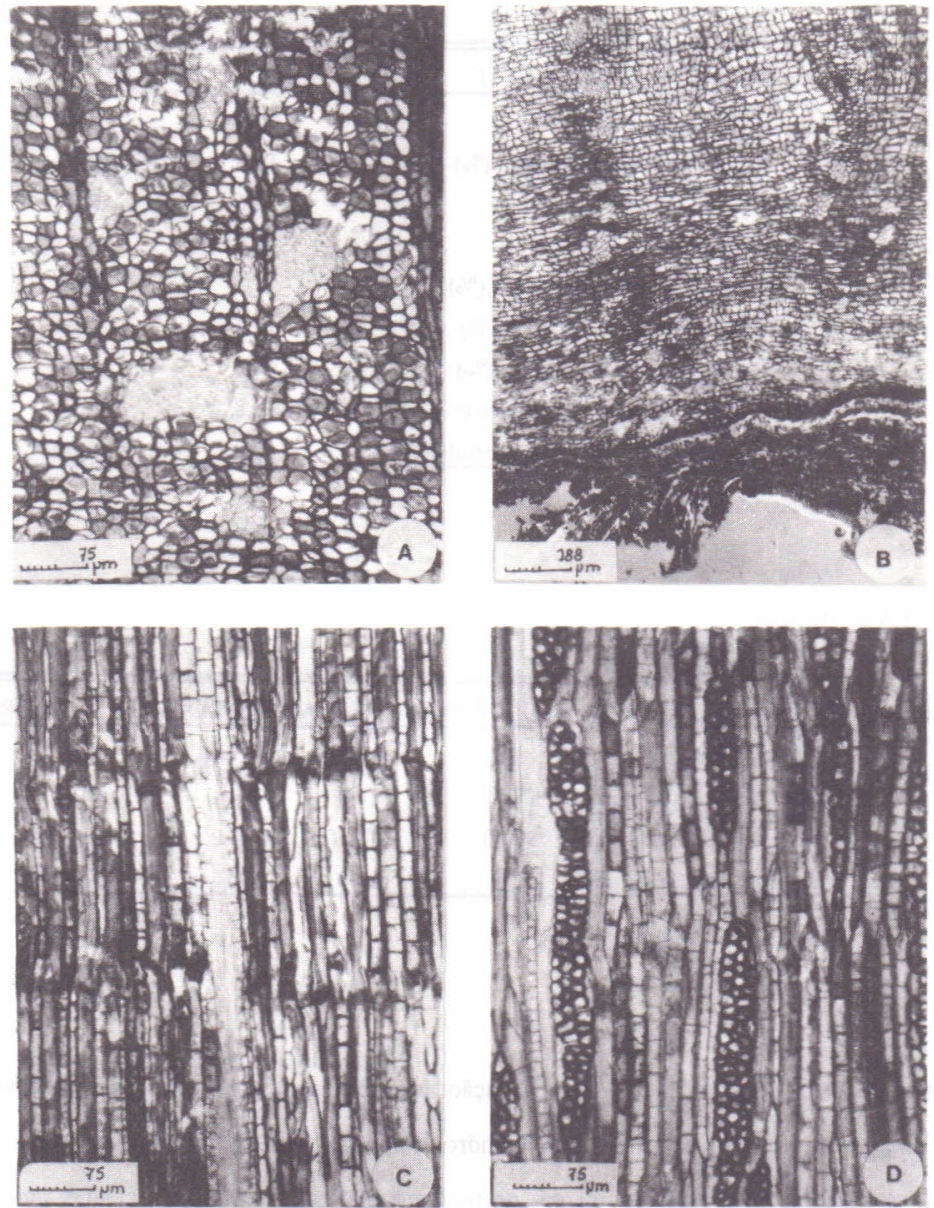

FIGURA 5. Fotomicrografias da casca. A. Casca interna em secção transversal: grupos de fibras floemáticas e elementos crivados. B. Cascas mediana e externa em secção transversal. C. Aspecto da casca interna em secão longitudinal radial, mostrando a estratificação de elementos crivados, células acompanhantes e células de parênquima floemático, além de um feixe de fibras, rodeado por séries de cristais em câmaras. D. Casca interna, em secção longitudinal tangencial.

especialização e corresponde, em seus caracteres mais relevantes, ao descrito em obras clássicas para a familia Leguminosae. RECORD \& HESS (1949), METCALFE \& CHALK (1972), TORTORELLI, (1956) e COZZO (1951), dentre outros, destacam para o xilema secundário das 
Leguminosas, a predominância de placas de perfuração simples, elementos vasculares curtos, pontoações intervasculares alternas e ornamentadas, parênquima paratraqueal, fibras libriformes e raios homogêneos.

A presença deste último caráter em Mimosa scabrella permite distinguir, de acordo com BARETTA-KUIPERS $(1980,81)$, a sub-familia Mimosoideae, dentro das Leguminosas. Este aspecto corresponde a uma das tendências evolutivas mais notáveis nesta familia botânica, partindo da relativamente primitiva sub-familia Caesalpinioideae. A presença de estratificação, observada na espécie em estudo, embora incomum em Mimosoideas, já havia sido referida por COZZO (1951) para Mimosa adpressa, além da própria bracatinga. MARCHIORI (1980.a), também descreveu o caráter para Mimosa taimbensis Burk. e Mimosa pseudincana Burk. var. discolor Burk., destacando o arranjo "bastante regular, de elementos vasculares e parênquima axial", além da ocorrência de raios tipicamente heterogêneos. A presença de estratificação na madeira de Mimosa scabrella pode, por outro lado, ser interpretada como indicativa de uma maior especialização do xilema, em comparação com as espécies do gênero desprovidas do caráter.

COZZO (1951), o autor que estudou com maior profundidade a anatomia da madeira em Mimosa sp., destaca sua heterogeneidade estrutural, em virtude da ampla variação observada entre suas espécies. Com relação às demais referências de COZZO (1951), foi confirmada a presença de poros geralmente solitários ou em curtos múltiplos, de raios predominantemente trisseriados e com abundantes bi e tetrasseriados, além de parênquima axial pouco abundante.

Com relação à anatomia da casca, os caracteres mais importantes observados em Mimosa scabrella correspondem ao descrito por ROTH (1977) para a sub-família.

Para a identificação da espécie em estudo, cabe ainda ressaltar a presença de liber duro em pequenos grupos na casca interna, envolvidos por células parenquimáticas geralmente cristaliferas, o crescimento de dilatação dos raios na casca mediana e a formação de uma estreita casca externa, composta por sucessivas peridermes.

\section{REFERÊNCIAS BIBLIOGRÁFICAS}

1. BARETTA-KUIPERS, T. The wood structure of leguminous tribes: their classification by ray and parenchyma features. For. Prod. Abstr., 3(8): 1.784, 1980. (Resumo).

2. BARETTA-KUIPERS, T. Wood Anatomy of Leguminosae: its relevance to Taxonomy. In: POLHILL, R.M. \& RAVEN, P.H. Advances in Legume Systematics. 1981. p. 677-715. 
3. BARNEBY, R.C. The genus Mimosa (Mimosaceae) in Bahia, Brazil: new taxa and nomenclatural adjustment. Brittonia, 37(2): 125-153, 1985.

4. BARRICHELLO, L.E.G. Celulose sulfato de bracatinga. In: CONGRESSO FLORESTAL BRASILEIRO, 1, 1968, Curitiba, 1968. Anais... Curitiba, 1971. p. 43-46.

5. BARRICHELLO, L.E.G. \& FOELKEL, C.E.B. Utilização da madeira de essências florestais nativas na obtenção de celulose: bracatinga (Mimosa bracatinga), embaúba (Cecropia sp.), caixeta (Tabebuia cassinoides) e boleira (Johannesia princeps). IPEF, 10: 43-56, 1975.

6. BENTHAM, G. Revision of the suborder Mimoseae. Transact. Linn. Soc. London, 30: 335 664. 1875 .

7. BROTERO, F.A. Tabelas de Resultados Obtidos para Madeiras Nacionais. São Paulo, Instituto de Pesquisas Tecnológicas, 1956. Bol. $\mathrm{n}^{\circ} 31.60 \mathrm{p}$

8. BÜHRER, N.E. Estudos para obtenção de carvão ativo vegetal. Arq. Biol. Tecn., 7: 103-121, 1952.

9. BURGER, L.M. Estudo anatômico do xilema secundário de sete espécies nativas do gênero Dalbergia, Leguminosae Faboideae. Curitiba, UFPR, 1979. 184 p. Dissertação (Mestrado). Curso de Pós-Graduação em Engenharia Florestal, 1979. 184 p. Universidade Federal do Paraná, 1979.

10. BURKART, A. Las especies de Mimosa de la Flora Argentina. Darwiniana, 8(1): 9-231, 1948.

11. BURKART, A. Las Leguminosas Argentinas Silvestres y Cultivadas. Buenos Aires, ACME, 1952. $569 \mathrm{p}$.

12. BURKART, A. Leguminosae. In: PARODI, L.R. Enciclopedia Argentina de Agricultura y Jardineria. Buenos Aires, ACME, 1959. Vol 1. p. 443-512.

13. BURKart, A. Leguminosae. In: CABRERA, A.L. Flora de la Província de Buenos Aires. Buenos Aires, Coleccion Cientifica del INTA, 1967. Tomo IV. p. 394-647.

14. BURKART, A. Leguminosas Mimosoideas. In: REITZ, R. Flora Ilustrada Catarinense. Itajaí, Herbário Barbosa Rodrigues, 1979. 299 p.

15. BURKART, A. Leguminosas. In: BURKART, A.; BURKART, N. S.T. de \& BACIGALUPO, N.M. Flora Ilustrada de Entre Rios (Argentina). Buenos Aires, Coleccion Cientifica del INTA, 1987. Tomo 6, n³, p. 442-738.

16. COPANT. COMISION PANAMERICANA DE NORMAS TECNICAS. n 30, p. 1-019, nov. 1973.

17. COZZO, D. Anatomia del leño secundario de las leguminosas mimosoideas y caesalpinoideas argentinas silvestres y cultivadas. Rev. Inst. Nac. Ci. Nat. Ciencias Botanicas, 2(2): 63 $290,1951$.

18. DUJARDIN, E.P. Eine neue Holz-zellulosenfaerbung. Mikrokosmos, 53: 94. 1964.

19. FREUND, H. Handbuch der Mikroskopie in der Technik. Frankfurt, Umscham Verlag, 1970. Band V, Teil 2. 379 p.

20. HOEHNE, F.C. A bracatinga ou abaracaatinga. São Paulo, Sec. Agric. Ind. Com., 1930. $47 \mathrm{p}$. 
21. INOUE, M.T.; RODERJAN, C.V. \& KUNIYOSHI, Y.S. Projeto madeira do Paraná Curitiba, Fundação de Pesquisas Florestais do Paraná, FUPEF, 1984. 260 p.

22. JANKOWSKY, I.P.; CHIMELO, J.P.; CAVALCANTE, A. de A; GALINA, I.C.M. \& NAGAMURA, J.C.S. Madeiras Brasileiras. Caxias do Sul, Spectrum, 1990. Vol. 1. 172 p.

23. KLEIN, R.M. O aspecto dinâmico do pinheiro brasileiro. Sellowia, 12(12): 17-44, 1960.

24. MACCARI, A. \& MARCHIORI, J.N.C. Estudo anatômico do xilema secundário de Mimosa sparsa Benth. Ciência Florestal, 4: 145-155, 1994.

25. MAINIERI, C. Madeiras do litoral sul: Estados de São Paulo, Paraná e Santa Catarina Nomenclatura botânica e vulgar, características gerais e usos comuns. São Paulo, Secretaria da Agricultura, 1973. Bol. n³.84 p

26. MARCHIORI, J.N.C. Estudo anatômico do xilema secundário e da casca de algumas espécies dos gêneros Acacia e Mimosa, nativas no Estado do Rio Grande do Sul. Curitiba, UFPR, 1980 a. 186 f. Dissertação (Mestrado). Curso de Pós-Graduação em Engenharia Florestal. Universidade Federal do Paraná.

27. MARCHIORI, J.N.C. Comprovação da viabilidade de utilização da secção longitudinal tangencial para a determinação histométrica dos elementos axiais do xilema secundário. In: CONGRESSO FLORESTAL ESTADUAL, 4, 1980 b, Nova Prata, Anais... Nova Prata, 1980 b. p. $180-184$

28. MARCHIORI, J,.N.,C. A estrutura do xilema secundário de Mimosa daleoides Benth. (Leguminosae Mimosoideae). Ciência e Natura, 4: 107-113, 1982

29. MARCHIORI, J.N.C. Anatomia da madeira de Mimosa cruenta Benth. (Leguminosae Mimosoideae). Ciência e Natura, Santa Maria, 7: 73-81, 1985.

30. MARCHIORI, J.N.C. Ontogenia do caule de Mimosa scabrella Benth. In: Anais do VI Congresso Florestal Estadual. Nova Prata, RS, 1988. p. 1167-1177.

31. MARCHIORI, J.N.C. Anatomia da madeira e casca do maricá, Mimosa bimucronata (DC.) Kuntze. Ciência Florestal, 3(1): 85-106, 1993.

32. METCALfE, C.R. \& CHALK, L. Anatomy of the Dicotyledons. Oxford, Clarendon Press, 1972. $1.500 \mathrm{p}$.

33. MUNSELL COLOR. Munsell Color Chart for Plant Tissues. Baltimore, 1952. 19 p.

34. PEDROSO, O. \& MATTOS, J.R. Estudo sobre Madeiras do Rio Grande do Sul. Porto Alegre, IPNRN, 1987. Bol. n²0. 181 p.

35. RAMBO, B. Estudo comparativo das Leguminosas Riograndenses. Anais Botânicos, 5: 107184,1953

36. RAMBO, B. Leguminosae Riograndenses. São Leopoldo, Instituto Anchietano de Pesquisas, 1966. Bol. $\mathrm{n}^{\circ} 23.166 \mathrm{p}$.

37. RECORD, S.J. \& HESS, R.W. Timbers of The New World. New Haven, Yale University Press, 1949. 640 p.

38. REITZ, R.; KLEIN, R.M. \& REIS, A. Projeto Madeira de Santa Catarina. Sellowia, 28: 1-320, 1978. 
39. REITZ, R.; KLEIN, R.M. \& REIS, A. Projeto Madeira do Rio Grande do Sul. Sellowia, 34-35: $1-525,1983$.

40. ROTH, I. Estructura anatomica de la corteza de algunas especies arboreas venezolanas de Mimosaceae. Acta Botanica Venezuelica, 12(1-4): 293-355, 1977.

41. SILVA, P.F. da. Características Físico-Mecânicas de espécies lenhosas do sul do Brasil. Porto Alegre, ITERS, 1967. Bol. n 42. 41 p

42. TORTORELLI, L.A. Maderas y Bosques Argentinos. uenos Aires, ACME, 1956. 910 p. 